\title{
Hepatitis C virus-related policy-making in Iran: a stakeholder and social network analysis
}

Masoud Behzadifar ${ }^{1}$, Hasan Abolghasem Gorji ${ }^{2}$, Aziz Rezapour ${ }^{1}$, Alireza Rezvanian ${ }^{3}$, Nicola Luigi Bragazzi ${ }^{4}$ and Soudabeh Vatankhah ${ }^{2^{*}}$

\begin{abstract}
Background: Hepatitis C virus (HCV) infection is a major public health challenge worldwide. Implementing policies to cope with this challenge requires commitment from all stakeholders at various levels, and all necessary resources should be mobilised. Support for various HCV-related stakeholders can reduce the challenges and obstacles that can be encountered during the programme implementation. The present study aims to identify all stakeholders involved with HCV-related policy-making in Iran at different steps (policy development, implementation and evaluation) and to characterise them in terms of interest, position, power and influence, in order to provide valuable information for appropriate decision-making and design. The present study can also serve as a case study for healthcare systems in other countries.
\end{abstract}

Method: An approach based on social network analysis was utilised. Data collected included relevant document searches and in-depth interviews to a sample of 18 key informants.

Results: Various stakeholders were found to be involved with HCV-related policies in Iran. The extent of their participation and support in policy-making varied. Specifically, international agencies had a high interest for HCVrelated policy-making, whereas media and members of the private sector were characterised by a medium interest and governmental and non-governmental bodies by a highly variable interest, ranging from low to high, depending on the specific organism. Moreover, media and members of the private sector, non-governmental institutions and international agencies were rated low in terms of position, whereas governmental actors were rated low to high. Media were rated medium in terms of power, whereas international agencies and members of the private sector were respectively rated low to medium and low. Non-governmental actors were rated low, whilst governmental bodies were rated low to high. Finally, media, members of the private sector and international agencies were rated medium in terms of influence, whereas non-governmental and governmental actors were respectively rated low to medium and low to high.

Conclusion: Policy-making involves trust, negotiation and integration of the different views of all stakeholders. Social network analysis was critical for identifying stakeholders and showing that, in Iran, involvement in HCVrelated policy-making is generally low. This information is of practical implication for policy-and decision-makers regarding the adoption of more favourable and effective strategies.

Keywords: HCV, policy-making, Iran, stakeholders analysis, social network analysis

\footnotetext{
* Correspondence: vatankhahsoudabeh@yahoo.com

${ }^{2}$ Department of Health Services Management, School of Health Management

and Information Sciences, Iran University of Medical Sciences, Tehran, Iran

Full list of author information is available at the end of the article
}

(c) The Author(s). 2019 Open Access This article is distributed under the terms of the Creative Commons Attribution 4.0 International License (http://creativecommons.org/licenses/by/4.0/), which permits unrestricted use, distribution, and reproduction in any medium, provided you give appropriate credit to the original author(s) and the source, provide a link to the Creative Commons license, and indicate if changes were made. The Creative Commons Public Domain Dedication waiver (http://creativecommons.org/publicdomain/zero/1.0/) applies to the data made available in this article, unless otherwise stated. 


\section{Background}

Hepatitis $\mathrm{C}$ virus (HCV) infection is a major public health challenge worldwide [1]. Chronic HCV infection can potentially lead to complications such as decompensated cirrhosis, liver failure and hepatocellular carcinoma [2]. Prevention, control, diagnosis and treatment are essential and should receive special attention from health decisionand policy-makers [3]. It is estimated that, globally, approximately 71 million people are affected by chronic HCV, and approximately 399,000 people die each year due to cirrhosis and hepatocellular carcinoma [4]. WHO reported that the highest prevalence of $\mathrm{HCV}$ was found in the Eastern Mediterranean Regional Organization (EMRO) region, with a rate of approximately $2.3 \%$, whilst Europe has a prevalence of approximately $1.5 \%$ [5]. Health policy- and decision-makers are working to implement $\mathrm{HCV}$-related programmes, mitigating the burden generated by the infection and providing effective treatment to patients [6]. Despite the lack of funding, efforts are made to reduce the health-related costs of the illness [7] and to provide a variety of financially sustainable programmes in order to reduce mortality and transmission of disease to the general population [8].

Implementing different policies to properly cope with $\mathrm{HCV}$ requires commitment from all stakeholders at the international, national and regional levels, with all facilities and resources that should be effectively mobilised to implement these policies. Support for various HCV-related stakeholders can reduce problems and obstacles that can be encountered during the implementation of the programme [9]. Support can include participation in policy-making, advising and suggesting appropriate policies, providing adequate funding needed to implement policies, discussing and resolving potential disagreements over policy implementation, and engaging with policy- and decision-makers to counteract the spreading of $\mathrm{HCV}$ [10].

Healthcare problems are complex, nonlinear and multi-factorial, and the various stakeholders involved in the process of policy-making may have a different impact on them [11]. Stakeholders include all the individuals, groups and organisations that can influence a given health-related issue. The diversity of views among stakeholders can affect the process of policy implementation [12]. Understanding and characterising stakeholders can raise awareness of the various dimensions underlying the decision-making process and potentially improve it. Stakeholder analysis is a systematic process that consists of identifying and characterising stakeholders in terms of interests, power and relationships to a given health-related policy [12].

Concerning HCV in Iran [13], some studies have been conducted on the prevalence of this infection in different groups. For example, the prevalence rate is $0.6 \%$ in the general population [14], $0.5 \%$ in blood donors [15], 41.3\% in injection drug users [16], 19\% in thalassemia patients [17], $28 \%$ in prisoners [18], $11 \%$ in haemodialysis patients [19], and 2.4\% in street children [20]. Based on these epidemiological findings, health policy- and decision-makers are implementing various ad hoc policies to cope with the disease [21]. However, as previously mentioned, the presence of different stakeholders with different interests and expectations towards health-related policies is one of the challenges to the implementation of various programmes [22], in that it is difficult to meet all expectations. The systematic identification and study of the stakeholders involved with a given policy through social network analysis (SNA) can enable the development of a constructive dialogue and of interactions based on their position, interests and impact on that policy [23]. Understanding the actors and their interests will make it possible to know how to develop and implement policies to counteract the spreading of $\mathrm{HCV}$. Stakeholders, in relation to a given health-related policy, are actors that can have a direct or indirect effect/influence and may increase or weaken the authority and effects of that policy [24].

The Ministry of Health and Medical Education (MoHME) is the main sponsor of health in Iran. The government, according to the different needs of the ministries and their programmes, provides the necessary budget. The parliament, according to the representatives of the delegates, ultimately approves the budget and adopts measures to implement it [25]. The MoHME allocates adequate financial resources for each programme and runs them through its medical universities (MUs) in all provinces. For other programmes and policies, other ministries can support the MoHME [26]. More specifically, the National Hepatitis Committee based at the Centres for Disease Control and Prevention, focuses on major HCV-related programmes in order to implement them. HCV-related policies are run through the Secretariat of the Supreme Council for Health and Food Security, in collaboration with other ministries if needed. Implementation of HCV-related plans is under the responsibility of the MoHME, health authorities and organisms, and other organisations that independently monitor the various processes through different quality indicators [27].

The present investigation aims to analyse the roles and characteristics of all stakeholders involved in HCV-related policies in Iran in order to provide valuable information for designing proper plans and making appropriate decisions about HCV-related policies. It may also serve as a case study for healthcare systems in other countries.

\section{Methods}

Stakeholder identification and analysis

Based on our aim, in order to examine the various dimensions and effects that stakeholders can have on 
HCV-related policies in Iran, the suggestions and the theoretical framework adopted by the World Bank [28] and by Varvasovsky et al. [24] were deemed appropriate and chosen for our study. As such, stakeholders were analysed and characterised based on four items, namely interest, position, power and influence.

Data were collected in two phases. Firstly, identification of the stakeholders (through interviews and documents) and, secondly, assessment of the view of participants towards stakeholder's roles (through expert opinions). In-depth interviews were conducted with key informants involved in $\mathrm{HCV}$-related programmes and policies. The full list of participants is shown in Table 1.

The main question framed was, 'who are the main HCV-related actors (such as organisations or institutions) involved with the processes of policy-making in Iran?' Within this step, HCV-related policy documents (including documents prepared and implemented by the government, the MoHME, the parliament, related organisations, media, health insurance, as well as WHO and non-governmental organisation (NGO) reports, news sites and scholarly literature on $\mathrm{HCV}$ policy-making) were also consulted and thoroughly inspected. The interviewees were selected through purposive sampling and snowballing. Participants who had experience and knowledge about $\mathrm{HCV}$-related programmes were interviewed and asked to introduce further actors involved with HCV-related policies. The interviews continued until a new actor was added and until data saturation was achieved. At the beginning of the interview, a consent form was given to the interviewees and they were informed about the aims of the present study. Interviewed participants included policy- and decision-makers, medical specialists, physicians, health department administrators, university professors, medical academicians,

Table 1 List of participants enrolled in the present study

\begin{tabular}{ll}
\hline Participants & No. \\
\hline Policy-makers & 3 \\
Specialist doctors & 2 \\
Nurses & 1 \\
Health centre staff & 1 \\
Hospital manager & 1 \\
Insurance manager & 1 \\
Judicial system & 1 \\
State Prisons and Security and Corrective Measures Organisation & 1 \\
Pharmaceutical companies managers & 1 \\
University professors & 2 \\
Non-governmental organisations & 2 \\
Iranian Red Crescent & 1 \\
Social media & 1 \\
\hline
\end{tabular}

journalists, nurses, hospital and insurance managers, and pharmacists. Interviews were conducted by two authors (MB and HAG). Based on the views of the participants, data were analysed by three authors (MB, HAG and AR). Subsequently, after collecting data, a list of all actors and stakeholders was obtained based on both interviews and document searches. All documents related to $\mathrm{HCV}$ in the field of prevention and treatment, of any type (meeting abstracts and conference proceedings, laws, regulations, rules, reports, articles, books, news and speeches) were evaluated (Table 2).

An ad hoc questionnaire was created in which stakeholders were rated in terms of interest, position, power and influence on HCV-related programmes and policies. Specifically, interest was defined as the degree of involvement with a given $\mathrm{HCV}$-related policy; position was defined as the number of connections or interactions with other actors involved in the process of HCV-related policy-making; power was defined as the degree or extent to which the stakeholder was deemed likely to affect and modify a certain HCV-related policy; and influence was defined as the amount of potential benefits (including money, facilities, mobilised resources and knowledge) relevant to HCV-related decisions. For each item of the questionnaire (interest, position, power and influence) a five-point answer (low, low-medium, medium, medium-high, and high) was possible.

During the second phase, the list containing all the names of stakeholders/actors involved with HCV-related programmes and policies in Iran and the questionnaire were sent by email to the interviewees. Finally, the average score of the participants for each stakeholder was computed.

\section{Social network analysis (SNA)}

A network characterised by properly balanced interactions among different stakeholders can lead to the development and implementation of adequate health-related policies [29]. Analysing this network can be a way to understand the structure of the process of policy-making and the relationships and interactions among the different stakeholders [30] in terms of relevance of each actor [31].

Table 2 List of HCV-related documents consulted in the present study

\begin{tabular}{ll}
\hline Type of document & Number \\
\hline Laws, regulations, rules & 8 \\
Guidelines, programmes & 12 \\
Websites & 52 \\
Reports & 10 \\
Scientific texts & 7 \\
Books & 8 \\
\hline
\end{tabular}


SNA is a sophisticated computational approach that shows the structure of the process of communication, relationships and interactions among the various stakeholders [32]. SNA shows also which parts of the network need more attention and dialogue, in order to ensure a proper healthcare policy-making process [33] and to achieve effective cooperation between different stakeholders [34]. SNA enables computing of network metrics, including degree, closeness, betweenness and eigenvector centralities.

Specifically, degree centrality is the number of direct relationships (links/edges connecting neighbouring nodes) that a stakeholder has [35]. Closeness centrality (or simply closeness) is the reciprocal of the sum of the length of the shortest interactions (paths, links or edges) between a stakeholder (node) and all the other actors (nodes) [36]. Betweenness centrality is based on the shortest paths, wherein a stakeholder can, indeed, reach other stakeholders (neighbouring nodes) through different paths, but only the shortest one is computed [37]. Eigenvector centrality is a proxy of the influence of a stakeholder and its importance in terms of connections with high-scoring ('central') nodes [38]. To carry out SNA, average scores were used based on the views of the participants, as well as the association of each organisation/institution with all the other organisations. Data were visualised and analysed using Gephi Version 0.92 software.

\section{Results}

\section{Stakeholder analysis}

The length of each interview varied between 10 and $15 \mathrm{~min}$. After interviewing a sample of 18 participants and reviewing related and pertinent documents, $29 \mathrm{HCV}$-related stakeholders in Iran were identified, as reported in Table 3.

Specifically, identified stakeholders included the Iranian Parliament (Majlis, directly elected with the vote of the people, involved in legislation, approval and monitoring of funds, and enforcement of the laws), the Judicial system, the State Prisons and Security and Corrective Measures Organisation (SPSCMO), the
MoHME, the Imam Khomeini Relief Foundation (IKRF, which sponsors and provides funding to poor people in the community), the Law Enforcement Force (LEF), governmental pharmaceutical companies (GPCs, involved in the preparation and production of medicines with the support of government funds), governmental insurances (GIs), MUs, the Iranian Blood Transfusion Organisation, the Ministry of Education (MoE), the State Welfare Organisation (SWO, involved in the improvement of social welfare, supporting unemployed people and developing ad hoc training programmes), the military forces, the Ministry of Sport and Youth (MoSY), the Ministry of Science, Research and Technology (MoSRT), the Iran Drug Control Headquarters (IDCH), the Municipalities, NGOs, scientific centres, the elites, the Iranian Red Crescent (IRC, which provides medicines and support to poor and ill people), the clerics, the Islamic Republic of Iran Broadcasting (IRIB, state-directed), news websites (society-directed), social media (society-directed), private pharmaceutical companies (PPCs, involved in the preparation and production of medicines with the financial support of the private sector), private insurances (PIs), WHO, and EMRO.

Stakeholders were classified into five groups, namely (1) governmental, (2) NGOs, (3) media, (4) members of the private sector, and (5) international agencies. More in detail, 16 stakeholders $(55.17 \%)$ related to $\mathrm{HCV}$-policies and programmes in Iran were governmental agencies. Six stakeholders $(20.68 \%)$ were NGOs. Three stakeholders (10.34\%) were political and media groups, whilst two stakeholders $(1.73 \%)$ were members of the private sector and international agencies.

The identified stakeholders were involved in different steps of the process of HCV-related policy-making. For instance, the MoHME was involved in policy development, implementation and evaluation, whereas SPSCMO in implementation, MUs in policy implementation and evaluation, and IDCH in policy development. Estimated interest, position, power and influence of key stakeholders involved with $\mathrm{HCV}$ policy-making in Iran are shown in Table 4.

Table 3 List of stakeholders involved with HCV-related policies and programmes in Iran

\begin{tabular}{ll}
\hline Category & Stakeholder \\
\hline $\begin{array}{l}\text { Governmental (16 } \\
\text { stakeholders) }\end{array}$ & $\begin{array}{l}\text { Parliament (Majlis), Judicial system, State Prisons and Security and Corrective Measures Organisation, Ministry of } \\
\text { Health and Medical Education, Imam Khomeini Relief Foundation, Law Enforcement Force, Government } \\
\text { pharmaceutical companies, Government insurances, Medical Universities, Iranian Blood Transfusion Organisation, } \\
\text { Ministry of Education, State Welfare Organisation, Military forces, Ministry of Sport and Youth, Ministry of Science, } \\
\text { Research and Technology, Iran Drug Control Headquarters }\end{array}$ \\
NGOs (6 stakeholders) & Municipalities, non-governmental organisations, Scientific centres, Elites, Iranian Red Crescent, Clerics \\
Media (3 stakeholders) & Islamic Republic of Iran Broadcasting, news websites, social media \\
Private sector (2 stakeholders) & Private pharmaceutical companies, private insurances \\
International agencies (2 & WHO, Eastern Mediterranean Regional Organization \\
stakeholders) &
\end{tabular}




\section{Interest analysis}

Among the stakeholders identified, the MoHME and the MUs (the main healthcare providers in Iran), the IBTO (the major provider of blood transfusion and blood donation), WHO and EMRO had the highest interest level towards HCV-related policies in Iran. Moreover, according to the scores given by the participants, the SPSCMO and PPCs had a medium-high interest for HCV-related policies. Prisoners, as one of the most high-risk groups for $\mathrm{HCV}$, have led the SPSCMO authorities to take an interest in harm reduction programmes for prisoners. PPCs have become interested in developing anti-HCV drugs in recent years. Elites, GIs, GPCs, IDCH, news websites, PIs, scientific centres and social media had medium interest for the process of $\mathrm{HCV}$-related policy-making. Stakeholders like the IKRF, the IRC, the
IRIB, the Judicial system, the LEF, NGOs, the Iranian Parliament, and SWO were found to have a lowmedium interest for HCV-related policy-making. Other stakeholders, such as clerics, municipalities, military forces, the MoE, the MoSRT, and the MoSY, had a low interest towards HCV-related policies. Thus, international agencies had a high interest for HCV-related policy-making, whereas media and members of the private sector were characterised by a medium interest and governmental bodies and NGOs by a highly variable interest, ranging from low to high, depending on the specific organism.

\section{Position analysis}

The MoHME has been recognised as the most important stakeholder in terms of position, having much

Table 4 Stakeholders involved with the process of HCV-related policy-making in Iran rated according to four items (interest, position, power and influence)

\begin{tabular}{|c|c|c|c|c|}
\hline Stakeholders & Interest & Position & Power & Influence \\
\hline Clerics & Low & Low & Low & Medium \\
\hline Eastern Mediterranean Regional Organization & High & Low & Low & Low-medium \\
\hline Elites & Medium & Low-medium & Low & High \\
\hline Government insurances & Medium & Medium-high & High & High \\
\hline Government pharmaceutical companies & Medium & Medium-high & Medium & High \\
\hline Imam Khomeini Relief Foundation & Low-medium & Low & Low & Medium \\
\hline Iran Drug Control Headquarters & Medium & Low & Medium-high & Medium \\
\hline Iranian Blood Transfusion Organisation & High & High & Medium & High \\
\hline Iranian Red Crescent & Low-medium & Low & Low & Medium \\
\hline Islamic Republic of Iran Broadcasting & Low-medium & Low & Low-medium & High \\
\hline Judicial system & Low-medium & Low & Medium-high & Medium \\
\hline Law Enforcement Force & Low-medium & Low & Low & Low-medium \\
\hline Medical Universities & High & High & Medium-high & High \\
\hline Military forces & Low & Low & Low & Medium \\
\hline Ministry of Education & Low & Low & Low & Medium \\
\hline Ministry of Health and Medical Education & High & High & High & High \\
\hline Ministry of Science, Research and Technology & Low & Low & Low & Low \\
\hline Ministry of Sport and Youth & Low & Low & Low & Medium \\
\hline Municipalities & Low & Low-medium & Low & Low \\
\hline News websites & Medium & Low & Medium & Medium \\
\hline Non-governmental organisations & Low-medium & Low & Low & Medium \\
\hline Parliament & Low-medium & Low & High & High \\
\hline Private insurances & Medium & Low & Low & Medium-high \\
\hline Private pharmaceutical companies & Medium-high & Low & Low & Medium \\
\hline Scientific centres & Medium & Low & Low & Medium-high \\
\hline Social media & Medium & Medium & Medium & Medium \\
\hline State Prisons and Security and Corrective Measures Organisation & Medium-high & High & High & Medium-high \\
\hline State Welfare Organisation & Low-medium & Medium & Medium & High \\
\hline WHO & High & Low & Medium & Medium \\
\hline
\end{tabular}


support for all its activities aimed at preventing, controlling and treating the disease. Additionally, stakeholders such as the IBTO, MUs and the SPSCMO were found to rank high in terms of position. Furthermore, GIs and GPCs were rated medium-high; they have, indeed, increased their support for reducing the costs and helping patients to adhere to treatment. Social media and SWO were rated medium, whereas municipalities and elites were rated low-medium in terms of position. PPCs also play a relatively important role in patient treatment programmes, despite being rated low together with clerics, the EMRO, the IKRF, the IDCH, the IRC, the IRIB, the LEF, the Judicial system, the military forces, the MoE, the MoSRT, the MoSY, news websites, NGOs, the Iranian Parliament, PIs, scientific centres, and WHO. Summarising, media as well as members of the private sector, NGOs and international agencies were rated low in terms of position, were governmental actors were rated low to high.

\section{Power analysis}

Participants rated the Parliament, the MoHME, GIs, and the SPSCMO as the most important HCV-related policy- and decision-makers in terms of power. In recent years, for instance, the SPSCMO has taken effective steps to control the disease through screening activities for prisoners in collaboration with the MoHME and the Judicial system. The latter, together with IDCH and the MUs, has a medium-high power. Actors like GPCs, the IBTO, news websites, social media, SWO, and WHO were found to have medium power, whereas the IRIB was rated low-medium. In general, most stakeholders, including clerics, the EMRO, elites, the IKRF, the IRC, LEF, military forces, the MoE, the MoSRT, the MoSY, municipalities, NGOs, PIs, PPCs, and scientific centres, were rated low in terms of power. Many organisations, despite having the institutional tasks and duties of controlling the spread of $\mathrm{HCV}$, do not use their power to influence $\mathrm{HCV}$-related plans and programmes in Iran. In summary, media were rated medium in terms of power, whereas international agencies and members of the private sector were respectively rated low to medium and low. Non-governmental actors were generally rated low, whilst governmental bodies were rated low to high.

\section{Influence analysis}

The MoHME, the Iranian Parliament, GPPs, GIs, MUs, the SWO, the IRIB, and the IBTO have a great influence on the policy of HCV-related screening and treatment programmes, as well as on the economic and financial plans. In general, the community elites have an important role to play in influencing policies, and they can provide Iran with more effective programmes by communicating effectively with policy- and decision-makers and expressing their views. PIs, scientific centres, and the SPSCMO were rated medium-high whereas clerics, the IKRF, the IDCH, the IRC, the Judicial system, the military forces, the MoE, the MoSY, news websites, NGOs, PPCs, social media and WHO were rated medium. EMRO and LEF were considered to have a low-medium influence, whereas the remainder (the MoSRT and municipalities) were judged to have a low influence. Summarising, media, members of the private sectors and international agencies were rated medium in terms of influence, whereas non-governmental and governmental actors were respectively rated low to medium and low to high.

\section{Social network analysis (SNA)}

The computed network metrics, including degree, closeness, betweenness and eigenvector centralities, are reported in Tables 5 and 6. Based on the SNA-related items, the MoHME had the highest rank for HCV-related policies in Iran, being the authority which writes, enforces and funds healthcare policies. Based on these findings, stakeholders like social media, news websites and the IRIB are the most centralised after the MoHME and Parliament. Network and node-level metrics are shown in Tables 5 and 6. Network maps based on interest, position, power and influence of the different stakeholders involved with $\mathrm{HCV}$ policy-making in Iran are respectively shown in Figs. 1, 2, 3 and 4.

\section{Discussion}

The findings of this study showed that the identified stakeholders have a different spectrum of interest, position, power and influence on HCV-related policies in Iran. Identifying these stakeholders is an important factor for succeeding in developing and implementing effective interventions and mobilising all necessary resources and facilities [39, 40]. Regarding HCV-related policy in Iran, the identified stakeholders directly and indirectly influence the formulation and implementation of policies. According to participant's viewpoints, the MoHME is the most important stakeholder identified.

Disagreements and different standpoints concerning the development and implementation of healthcare policies can be a challenge [41], despite negotiations being able to mitigate such contrasts and contribute to finding an optimal compromise [42]. In the case of HCV-related policies in Iran, a lack of cooperation has hindered a proper implementation of the plans [10]. Based on the ranks and metrics properties of the stakeholders, one of the noticeable findings of the present investigation is that, despite the fact that HCV has been properly identified as a challenge for Iran's health sector, many stakeholders believe that they could not do much. Indeed, 
Table 5 Network metrics, including degree, closeness, betweenness and eigenvector centralities, computed for the different stakeholders involved with HCV policy-making in Iran

\begin{tabular}{|c|c|c|c|c|}
\hline Stakeholders & $\begin{array}{l}\text { Degree } \\
\text { centrality }\end{array}$ & $\begin{array}{l}\text { Closeness } \\
\text { centrality }\end{array}$ & $\begin{array}{l}\text { Betweenness } \\
\text { centrality }\end{array}$ & $\begin{array}{l}\text { Eigenvector } \\
\text { centrality }\end{array}$ \\
\hline Ministry of Health and Medical Education & 29 & 1 & 74.85 & 1.00 \\
\hline Parliament & 25 & 0.90 & 26.18 & 0.97 \\
\hline Social media & 25 & 0.90 & 26.18 & 0.97 \\
\hline News websites & 25 & 0.90 & 26.18 & 0.97 \\
\hline Islamic Republic of Iran Broadcasting & 18 & 0.73 & 7.44 & 0.78 \\
\hline Law Enforcement Force & 17 & 0.71 & 9.01 & 0.73 \\
\hline Judicial system & 16 & 0.70 & 6.50 & 0.70 \\
\hline Clerics & 15 & 0.68 & 4.69 & 0.67 \\
\hline Elites & 14 & 0.66 & 2.64 & 0.66 \\
\hline Imam Khomeini Relief Foundation & 14 & 0.66 & 9.58 & 0.59 \\
\hline Municipalities & 13 & 0.65 & 2.49 & 0.61 \\
\hline Government insurances & 13 & 0.65 & 6.08 & 0.55 \\
\hline Medical Universities & 13 & 0.65 & 5.41 & 0.58 \\
\hline Iran Drug Control Headquarters & 13 & 0.65 & 1.69 & 0.63 \\
\hline $\begin{array}{l}\text { State Prisons and Security and Corrective Measures } \\
\text { Organisation }\end{array}$ & 12 & 0.63 & 1.23 & 0.59 \\
\hline State Welfare Organisation & 12 & 0.63 & 2.43 & 0.55 \\
\hline Scientific centres & 11 & 0.62 & 1.60 & 0.53 \\
\hline Non-governmental organisations & 11 & 0.62 & 1.11 & 0.54 \\
\hline Ministry of Science, Research and Technology & 9 & 0.59 & 0.74 & 0.43 \\
\hline Iranian Blood Transfusion Organisation & 9 & 0.59 & 1.00 & 0.41 \\
\hline Military forces & 8 & 0.58 & 0.21 & 0.41 \\
\hline Iranian Red Crescent & 8 & 0.58 & 0.56 & 0.40 \\
\hline Government pharmaceutical companies & 8 & 0.58 & 1.43 & 0.38 \\
\hline Ministry of Education & 8 & 0.58 & 0.30 & 0.42 \\
\hline Ministry of Sport and Youth & 7 & 0.57 & 0.09 & 0.38 \\
\hline WHO & 6 & 0.56 & 2.00 & 0.30 \\
\hline Private insurances & 4 & 0.53 & 0.14 & 0.16 \\
\hline Private pharmaceutical companies & 4 & 0.53 & 0.12 & 0.19 \\
\hline Eastern Mediterranean Regional Organization & 2 & 0.51 & 0.00 & 0.08 \\
\hline
\end{tabular}

Table 6 Network and node-level metrics

\begin{tabular}{ll}
\hline Parameter & Value \\
\hline Nodes & 29 \\
Edges & 184 \\
Density & 0.453 \\
Average degree & 12.69 \\
Average clustering coefficient & 0.746 \\
Number of triangles & 564 \\
Diameter & 2 \\
Average path length & 1.546 \\
\hline
\end{tabular}

many stakeholders tend to consider the disease merely as a priority of the MoHME.

The identified stakeholders showed different degrees of interest towards HCV-related policy. Their differing motivation can explain this [43]; for example, interest by the IKRF and SWO was found to be low despite being important organisations that help poor people. On the other hand, stakeholders rated high for position can have a high impact on other stakeholders. The political, economic, social and cultural status of each stakeholder indeed plays an important role in the process of policy-making. The power of stakeholders is one of the main factors and components of the development and implementation of health-related policies [44]. However, 


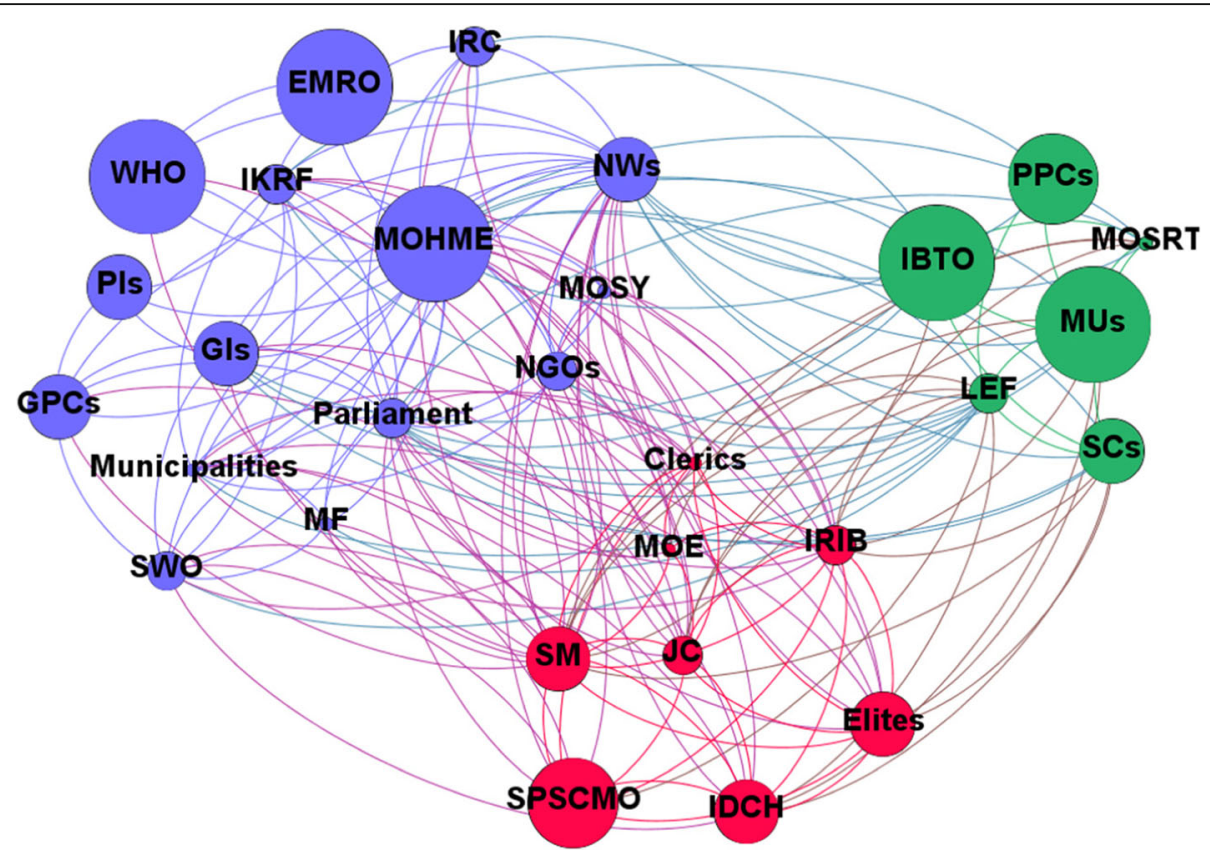

Fig. 1 Network map based on the interest of different stakeholders involved with HCV policy-making in Iran

regarding HCV-related policy in Iran, participation and involvement in political discussions for policy-making are generally low, and this is a challenge that can affect policy implementation by causing delays or resulting in failures.

Experts believe that, in order to improve policy and implementation, both top-down and bottom-up approaches should be used to allow continuous implementation of policies [45]. Specifically with regards to HCV policy in Iran, most decisions are taken by the MoHME, with a low participation of other stakeholders and a lack of appropriate dialogue with the bottom-up beneficiaries. Through a more intense political dialogue, these weaknesses could be somewhat reduced. Moreover, due to the limited financial resources and economic difficulties caused by international sanctions in Iran, not all

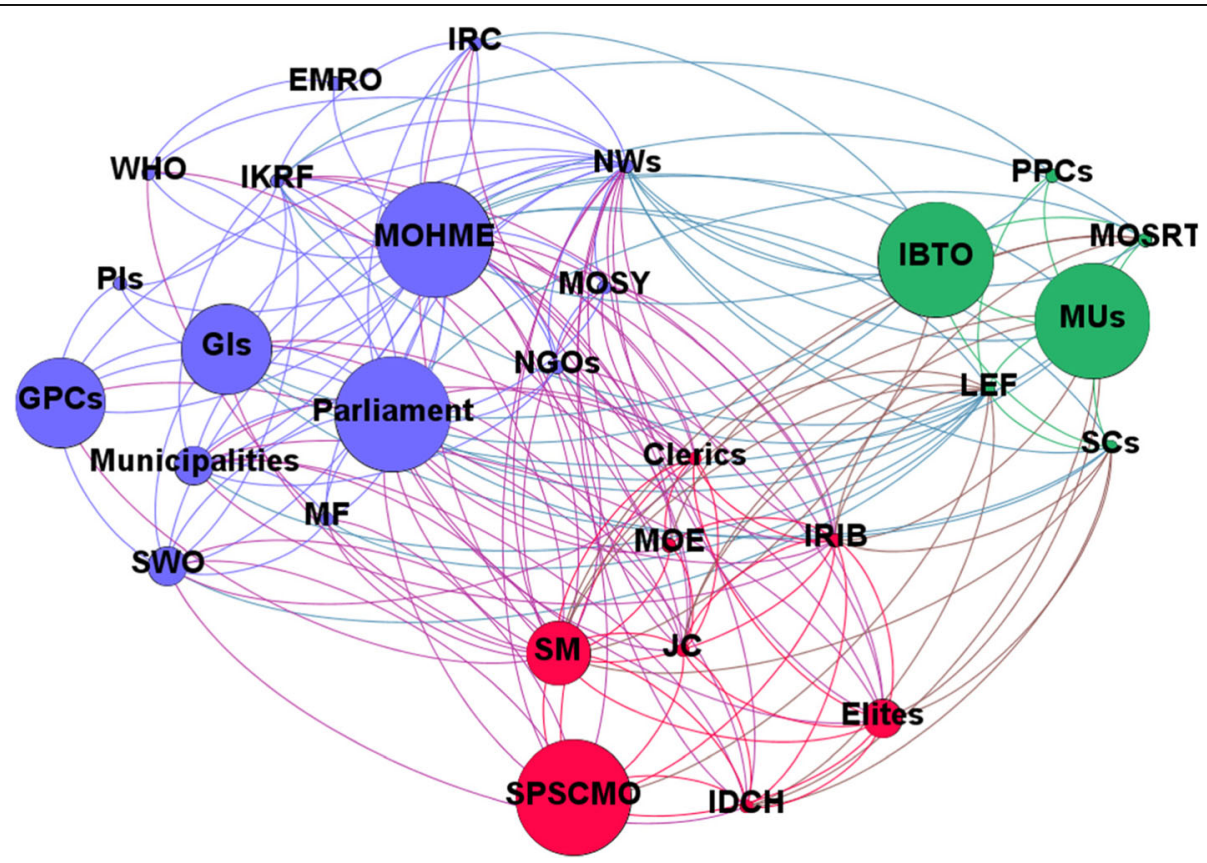

Fig. 2 Network map based on the position of different stakeholders involved with HCV policy-making in Iran 


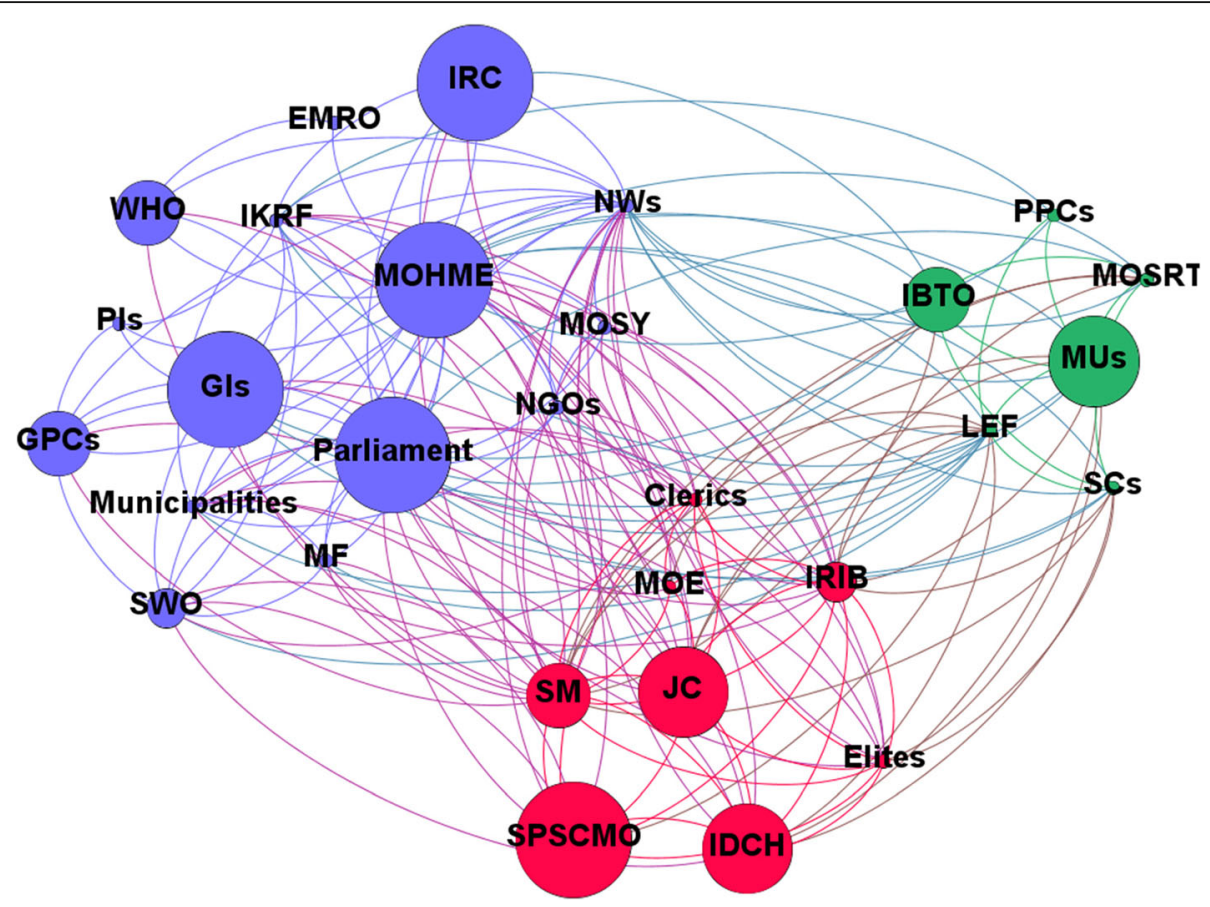

Fig. 3 Network map based on power of different stakeholders involved with HCV policy-making in Iran

the necessary financial resources for the treatment of patients are provided to every patient. Although some new financial resources have been planned since the implementation of the Health Transformation Plan in Iran, these resources have not been fully allocated [46].
Stakeholders can influence policies based on their own characteristics and their effects can be positive or negative [47]. Regarding the prevention dimension, IRIB, social media, news websites and clerics have a great influence on society. Unfortunately, despite this high

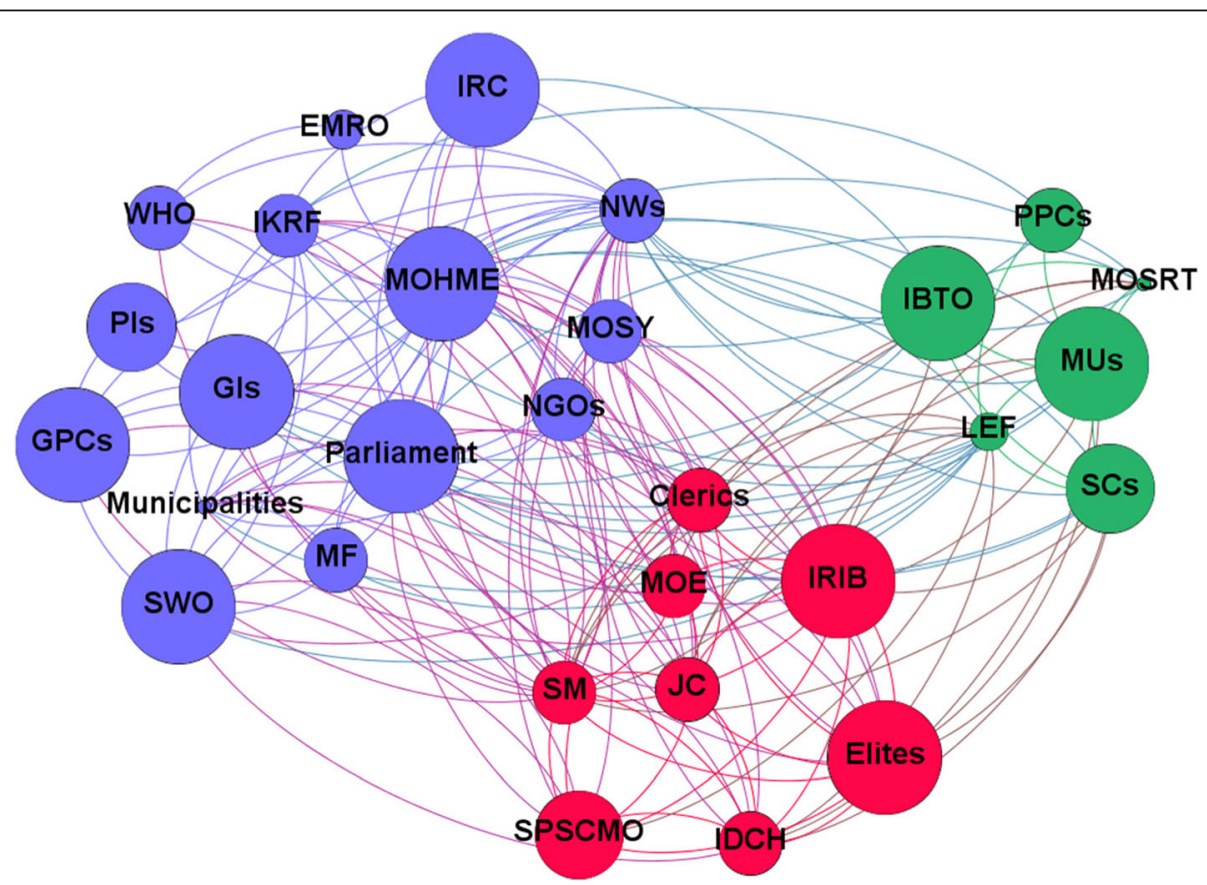

Fig. 4 Network map based on influence of different stakeholders involved with HCV policy-making in Iran 
potential, because of certain cultural problems associated with $\mathrm{HCV}$, such as stigma, they have not been successful in fulfilling the mission of raising awareness. However, in recent years, the MoHME has tried to reduce HCV-related stigma, and stakeholders are working with the MoHME to raise awareness among the general population.

The findings of the present study showed that network density was generally low. Collaboration and interactions among all involved stakeholders at all levels should be extensively adopted to address important issues such as HCV. They should have a comprehensive understanding of the magnitude and impact of their collaboration.

Cultural factors and community views can affect health policies $[48,49]$. In the Iranian society, stigma is still high and, therefore, SNA findings showed that those who are responsible for spreading information and raising awareness should have a more active participation and a greater role in preventive policies; the centrality of stakeholders such as social media, news websites and the IRIB emphasised this issue.

Finally, the findings of this study showed that the ongoing dialogue between stakeholders favours more sensitivity and empowerment, potentially resulting in an integration of some programmes. Consultation with all involved stakeholders can help in the design and implementation of adequate policies.

\section{Conclusion}

The findings of this study showed that there are many stakeholders involved with HCV-related policy in Iran. The extent of their participation and support in the process of policy-making is different and variable. In general, involvement in HCV-related policy-making is low. This information has practical implications for policy- and decision-makers, helping them to adopt more favourable and effective strategies. HCV-related policy-making and decision processes should not be handled by the MoHME alone, but should receive support and advocacy from all involved stakeholders. This is essential for succeeding in the ambitious goal of managing and controlling this disease. Proper policy-making involves trust, ongoing negotiations, integration and implementation of the different views of all involved stakeholders. In the present investigation, SNA was a critical point for identifying stakeholders as well as gaps and weaknesses so that policy- and decision-makers can have a more comprehensive understanding of health issues and processes and make better-informed decisions.

\section{Abbreviations}

EMRO: Eastern Mediterranean Regional Organization; Gls: government insurances; GPC: government pharmaceutical companies; HCV: hepatitis C virus; IDCH: Iran Drug Control Headquarters; IKRF: Imam Khomeini Relief Foundation; IRC: Iranian Red Crescent; IRIB: Islamic Republic of Iran
Broadcasting; LEF: Law Enforcement Force; MoE: Ministry of Education; MoHME: Ministry of Health and Medical Education; MoSRT: Ministry of Science, Research and Technology; MoSY: Ministry of Sport and Youth; MUs: medical universities; NGOs: non-governmental organisations; PIs: private insurances; PPCs: private pharmaceutical companies; SNA: social network analysis; SPSCMO: State Prisons and Security and Corrective Measures Organisation; SWO: State Welfare Organisation

\section{Acknowledgements}

This study was part of a PhD thesis supported by the School of Health Management, Iran University of Medical Sciences, Iran (IUMS/SHMIS_1396/ 9423557001).

\section{Funding}

Not applicable.

\section{Availability of data and materials \\ Not applicable.}

\section{Authors' contributions}

$M B, S V$ and HAG designed the study. MB, HAG and SV collated data. MB and Alireza R analysed data. SV, HAG, Aziz R, NLB and MB performed a final revision and grammar editing of the manuscript. All authors read and approved the final manuscript.

\section{Ethics approval and consent to participate}

The study protocol was reviewed and approved by the Ethics Committee of the School of Health Management and Information Sciences, Iran University of Medical Sciences.

\section{Consent for publication}

Not applicable.

\section{Competing interests}

The authors declare that they have no competing interests.

\section{Publisher's Note}

Springer Nature remains neutral with regard to jurisdictional claims in published maps and institutional affiliations.

\section{Author details}

${ }^{1}$ Health Management and Economics Research Center, Iran University of Medical Sciences, Tehran, Iran. ²Department of Health Services Management, School of Health Management and Information Sciences, Iran University of Medical Sciences, Tehran, Iran. ${ }^{3}$ School of Computer Science, Institute for Research in Fundamental Sciences (IPM), Tehran, Iran. ${ }^{4}$ School of Public Health, Department of Health Sciences (DISSAL), University of Genoa, Genoa, Italy.

Received: 18 December 2018 Accepted: 27 March 2019

Published online: 16 April 2019

\section{References}

1. Lanini S, Easterbrook PJ, Zumla A, Ippolito G. Hepatitis C: global epidemiology and strategies for control. Clin Microbiol Infect. 2016;22(10): 833-8.

2. Moore KJ, Gauri A, Koru-Sengul T. Prevalence and sociodemographic disparities of hepatitis C in baby boomers and the US adult population. J Infect Public Health. 2019;12(1):32-6.

3. Bocour A, Greene SK, Laraque F, Winters A. Estimating the prevalence of chronic hepatitis $C$ virus infection in new York City, 2015. Epidemiol Infect. 2018;146(12):1537-42

4. World Health Organization. Hepatitis C, Key Facts 2018. http://www.who.int/ news-room/fact-sheets/detail/hepatitis-c. Accessed 11 Apr 2019

5. World Health Organization. Global Hepatitis Report, 2017. 2017. http:// www.who.int/hepatitis/publications/global-hepatitis-report2017/en/. Accessed 11 Apr 2019

6. Bosques-Padilla FJ, Vázquez-Elizondo G, Villaseñor-Todd A, Garza-González E, Gonzalez-Gonzalez JA, Maldonado-Garza HJ. Hepatitis C virus infection in health-care settings: medical and ethical implications. Ann Hepatol. 2010; 9(Suppl):132-40 
7. Chidi AP, Bryce CL, Donohue JM, Fine MJ, Landsittel D, Myaskovsky L, et al. Economic and public health impacts of policies restricting access to hepatitis C treatment for MedicAid patients. Value Health. 2016;19(4):326-34.

8. Chhatwal J. Hepatitis C screening: from modeling to public health policy. Clin Infect Dis. 2018;66(3):385-6.

9. Wylie L, Hutchinson S, Liddell D, Rowan N. The successful implementation of Scotland's hepatitis $C$ action plan: what can other European stakeholders learn from the experience? A Scottish voluntary sector perspective. BMC Infect Dis. 2014;14(Suppl 6):S7.

10. Suthar $A B$, Harries AD. A public health approach to hepatitis $C$ control in low- and middle-income countries. PLoS Med. 2015;12(3):e1001795.

11. Schiller C, Winters M, Hanson HM, Ashe MC. A framework for stakeholder identification in concept mapping and health research: a novel process and its application to older adult mobility and the built environment. BMC Public Health. 2013;2013:428.

12. Brugha R, Varvasovszky Z. Stakeholder analysis: a review. Health Policy Plan. 2000;15(3):239-46

13. Zare F, Fattahi MR, Sepehrimanesh M, Safarpour AR. Economic burden of hepatitis $C$ virus infection in different stages of disease: a report from southern Iran. Hepat Mon. 2016;16(4):e32654.

14. Mirminachi B, Mohammadi Z, Merat S, Neishabouri A, Sharifi AH, Alavian SH, et al. Update on the prevalence of hepatitis $\mathrm{C}$ virus infection among Iranian general population: a systematic review and meta-analysis. Hepat Mon. 2017;17(12):e42291.

15. Khodabandehloo M, Roshani D, Sayehmiri K. Prevalence and trend of hepatitis C virus infection among blood donors in Iran: a systematic review and meta-analysis. J Res Med Sci. 2013;18(8):674-82.

16. Nematollahi S, Ayubi E, Almasi-Hashiani A, Mansori K, Moradi Y, Veisani Y, et al. Prevalence of hepatitis $C$ virus infection among high-risk groups in Iran: a systematic review and meta-analysis. Public Health. 2018;161:90-8.

17. Behzadifar M, Gorji HA, Bragazzi NL. The prevalence of hepatitis $C$ virus infection in thalassemia patients in Iran from 2000 to 2017: a systematic review and meta-analysis. Arch Virol. 2018;163(5):1131-40.

18. Behzadifar M, Gorji HA, Rezapour A, Bragazzi NL. Prevalence of hepatitis C virus infection among prisoners in Iran: a systematic review and metaanalysis. Harm Reduct J. 2018;15(1):24.

19. Ghorbani NR, Djalalinia S, Modirian M, Abdar ZE, Mansourian M, Gorabi AM, et al. Prevalence of hepatitis $C$ infection in Iranian hemodialysis patients: an updated systematic review and meta-analysis. J Res Med Sci. 2017;22:123.

20. Behzadifar M, Gorji HA, Rezapour A, Bragazzi NL. Prevalence of hepatitis C virus among street children in Iran. Infect Dis Poverty. 2018;7(1):88.

21. Lankarani KB, Alavian SM, Peymani P. Health in the Islamic Republic of Iran challenges and progresses. Med J Islam Repub Iran. 2013;27(1):42-9.

22. Twine R, Kahn K, Scholtz A, Norris SA. Involvement of stakeholders in determining health priorities of adolescents in rural South Africa. Glob Health Action. 2016;9:29162. https://doi.org/10.3402/gha.v9.29162.

23. Huotari P, Havrdová Z. Stakeholders' roles and responsibilities regarding quality of care. Int J Health Care Qual Assur. 2016;29(8):864-76.

24. Varvasovszky Z, Brugha R. A stakeholder analysis. Health Policy Plan. 2000; 15(3):338-45.

25. Zakeri M, Olyaeemanesh A, Zanganeh M, Kazemian M, Rashidian A, Abouhalaj $\mathrm{M}$, et al. The financing of the health system in the Islamic Republic of Iran: a National Health Account (NHA) approach. Med J Islam Repub Iran. 2015;29:243.

26. Almaspoor Khangah H, Jannati A, Imani A, Salimlar S, Derakhshani N, Raef B. Comparing the health care system of Iran with various countries. Health Scope. 2017;6(1):e34459.

27. Yousefi M, Akbari Sari A, Arab M, Oliaeemanesh A. Methods of resource allocation based on needs in health systems, and exploring the current Iranian resource allocation system. Hakim Health Sys Res. 2010;13(2):80-90,

28. World Bank. Stakeholder Analysis. 2001. http://www1.worldbank.org/ publicsector/anticorrupt/PoliticalEconomy/stakeholderanalysis.htm. Accessed 1 Mar 2019.

29. Blanchet $\mathrm{K}$, James P. How to do (or not to do) ... A social network analysis in health systems research. Health Policy Plan. 2012;27(5):438-46.

30. Uddin S, Mahmood H, Senarath U, Zahiruddin Q, Karn S, et al. Analysis of stakeholders networks of infant and young child nutrition programmes in Sri Lanka, India, Nepal, Bangladesh and Pakistan. BMC Public Health. 2017; 17(Suppl 2):405.

31. Schiller C, Winters M, Hanson HM, Ashe MC. A framework for stakeholder identification in concept mapping and health research: a novel process and its application to older adult mobility and the built environment. BMC Public Health. 2013:13:428.

32. O'Malley AJ, Marsden PV. The analysis of social networks. Health Serv Outcomes Res Methodol. 2008:8(4):222-69.

33. Sales AE, Estabrooks CA, Valente TW. The impact of social networks on knowledge transfer in long-term care facilities: protocol for a study. Implement Sci. 2010;5:49.

34. Chambers D, Wilson P, Thompson C, Harden M. Social network analysis in healthcare settings: a systematic scoping review. PLoS One. 2012;7(8): e41911.

35. Boyd DM, Ellison NB. Social network sites: definition, history, and scholarship. J Comput Commun. 2007;13:210-30.

36. Latora V, Marchiori M. A measure of centrality based on network efficiency. New J Phys. 2007;9(6):188.

37. Grunspan DZ, Wiggins BL, Goodreau SM. Understanding classrooms through social network analysis: a primer for social network analysis in education research. CBE Life Sci Educ. 2014;13(2):167-79.

38. Ahajjam S, Badir H. Identification of influential spreaders in complex networks using HybridRank algorithm. Sci Rep. 2018;8(1):11932.

39. Namazzi G, Kiwanuka SN, Waiswa P, Bua J, Okui O, Allen AK, et al. Stakeholder analysis for a maternal and newborn health project in eastern Uganda. BMC Pregnancy Childbirth. 2013;13:58.

40. Kananura RM, Ekirapa-Kiracho E, Paina L, Bumba A, Mulekwa G, NakigandaBusiku D, et al. Participatory monitoring and evaluation approaches that influence decision-making: lessons from a maternal and newborn study in eastern Uganda. Health Res Policy Syst. 2017:15(Suppl 2):107.

41. Strehlenert H, Richter-Sundberg L, Nyström ME, Hasson H. Evidenceinformed policy formulation and implementation: a comparative case study of two national policies for improving health and social care in Sweden. Implement Sci. 2015;10:169.

42. Fretheim A, Oxman AD, Lavis JN, Lewin S. SUPPORT tools for evidenceinformed policymaking in health 18: planning monitoring and evaluation of policies. Health Res Policy Syst. 2009;7(Suppl 1):S18.

43. Concannon TW, Fuster M, Saunders T, Patel K, Wong JB, Leslie LK, et al. A systematic review of stakeholder engagement in comparative effectiveness and patient-centered outcomes research. J Gen Intern Med. 2014;29(12): 1692-701.

44. Mwisongo A, Nabyonga-Orem J, Yao T, Dovlo D. The role of power in health policy dialogues: lessons from African countries. BMC Health Serv Res. 2016;16(Suppl 4):213.

45. Huang $\mathrm{T}$, Cawley JH, Ashe M, Costa SA, Frerichs LM, Zwicker L, et al. Mobilisation of public support for policy actions to prevent obesity. Lancet. 2015;385(9985):2422-31.

46. Olyaeemanesh A, Behzadifar M, Mousavinejhad N, Behzadifar M, Heydarvand S, Azari S, et al. Iran's health system transformation plan: a SWOT analysis. Med J Islam Repub Iran. 2018:32:39.

47. Malfait S, Van Hecke A, Hellings J, De Bodt G, Eeckloo K. The impact of stakeholder involvement in hospital policy decision-making: a study of the hospital's business processes. Acta Clin Belg. 2017;72(1):63-71.

48. Rubel AJ, Garro LC. Social and cultural factors in the successful control of tuberculosis. Public Health Rep. 1992;107(6):626-36.

49. Plough AL. Building a culture of health: a critical role for public health services and systems research. Am J Public Health. 2015;105(Suppl 2):S150-S2.

Ready to submit your research? Choose BMC and benefit from:

- fast, convenient online submission

- thorough peer review by experienced researchers in your field

- rapid publication on acceptance

- support for research data, including large and complex data types

- gold Open Access which fosters wider collaboration and increased citations

- maximum visibility for your research: over $100 \mathrm{M}$ website views per year

At $\mathrm{BMC}$, research is always in progress.

Learn more biomedcentral.com/submission 